\title{
Adsorption of Tetramethylthiourea in the Presence of Cationic Detergent at Interface Electrode / Aqueous Perchlorate Solutions
}

\author{
Malgorzata Klin, Jolanta Nieszporek, Dorota Sieńko, Dorota Gugala-Fekner, and Jadwiga Saba* \\ Department of Analytical Chemistry and Instrumental Analysis, Faculty of Chemistry, Maria Curie-Sktodowska University, \\ Maria Curie-Skłodowska Sq.3, 20-031 Lublin, Poland \\ RECEIVED OCTOBER 28, 2010; REVISED MARCH 16, 2011; ACCEPTED APRIL 29, 2011
}

\begin{abstract}
The mixed adsorption layers of tetramethylthiourea and a cationic detergent formed at electrode surface in $\mathrm{NaClO}_{4}\left(1 \mathrm{~mol} \mathrm{dm}^{-3}\right)$ are described. The systems were characterized by the measurement of differential capacity, zero charge potential, and surface tension at this potential. The data were analyzed to obtain the surface pressure and relative surface excess of tetramethylthoiurea as a function of electrode charge at bulk concentration of studied compounds. It was stated that the adsorbing tetramethylthoiurea molecule pushed out the water molecule instead of the detergent molecule from the electrode surface. The constants of the Frumkin and corrected Flory-Huggins isotherm point to a decreased TMTU adsorption energy in the cationic detergents presence and stronger repulsive interaction. Electrostatic parameters of the inner layer were assigned. In the range of more negative potentials, mixed adsorption layers were described by investigating the kinetics of the $\mathrm{Zn}^{2+}$ ions electroreduction as a piloting ion. (doi: $10.5562 /$ cca1791)
\end{abstract}

Keywords: adsorption, cationic detergent, mixed adsorption layer, mercury electrode, tetramethylthiourea

\section{INTRODUCTION}

Adsorption processes play an important role in the phenomena occurring at interfaces including natural and technologically induced phase boundaries. These processes are conveniently studied by electrochemical methods. Spontaneous adsorption of sulphurcontaining molecules from solutions onto metals to form close-packed and oriented monolayers provide a convenient method to assign desired chemical or physical properties to surfaces. ${ }^{1,2}$ By using a mixture of adsorbates, it is therefore possible to introduce different chemical functionalities on a surface. ${ }^{3-5} \mathrm{~A}$ large number of electrochemical studies dealing with adsorption of organic compounds are based on the differential capacitance of the double layer in relation to the bulk concentration and to the electrode potential measurements. The most intensive and extensive investigations were performed on the mercury electrode. ${ }^{6-8}$ Electrode surfaces properties are substantially modified by adsorbed molecules which strongly affect the electrode reactions. It is important to know the adsorption behaviour of organic additive when studying its influence mechanisms on the process of metal electrocrystallization and electrochemical cor- rosion. The results presented in this paper concern tetramethylthiourea (TMTU) adsorption parameters, the electrostatic parameters of the inner layer as well as kinetic parameters of $\mathrm{Zn}^{2+}$ ions reduction in $7.5 \times 10^{-4} \mathrm{~mol} \mathrm{dm}{ }^{-3}$ octyltrimethylammonium bromide $\left(\mathrm{C}_{11} \mathrm{H}_{26} \mathrm{NBr}\right)+\mathrm{TMTU}+1 \mathrm{~mol} \mathrm{dm}{ }^{-3} \mathrm{NaClO}_{4}$. The chosen detergents concentration was lower than its critical point of micellation. Adsorption mechanism of used organic substances was different, the cationic detergent underwent physical adsorption whereas TMTU chemical adsorption. Additionally, TMTU's adsorption parameters in aqueous solutions are presented in the literature. ${ }^{9-11}$ The investigated compounds had an inverse effect on the kinetics of $\mathrm{Zn}^{2+}$ ions electroreduction. The studies on $\mathrm{Zn}^{2+}$ ions reduction kinetics as piloting ions allow on monitoring the used organic compounds adsorption equilibrium at potentials distant from maximum adsorption potential. This paper is only a part of complex studies on mixed adsorption layers: TMTU in the presence of different types of biological detergents. The later are used to separate nucleic acids and proteins from their cellular structures. The choice of $\mathrm{NaClO}_{4}$ solution resulted from the fact that $\mathrm{ClO}_{4}^{-}$ions caused the strongest disruption in the water structure. ${ }^{12}$

\footnotetext{
*Author to whom correspondence should be addressed. (E-mail: jsaba@poczta.umcs.lublin.pl)
} 


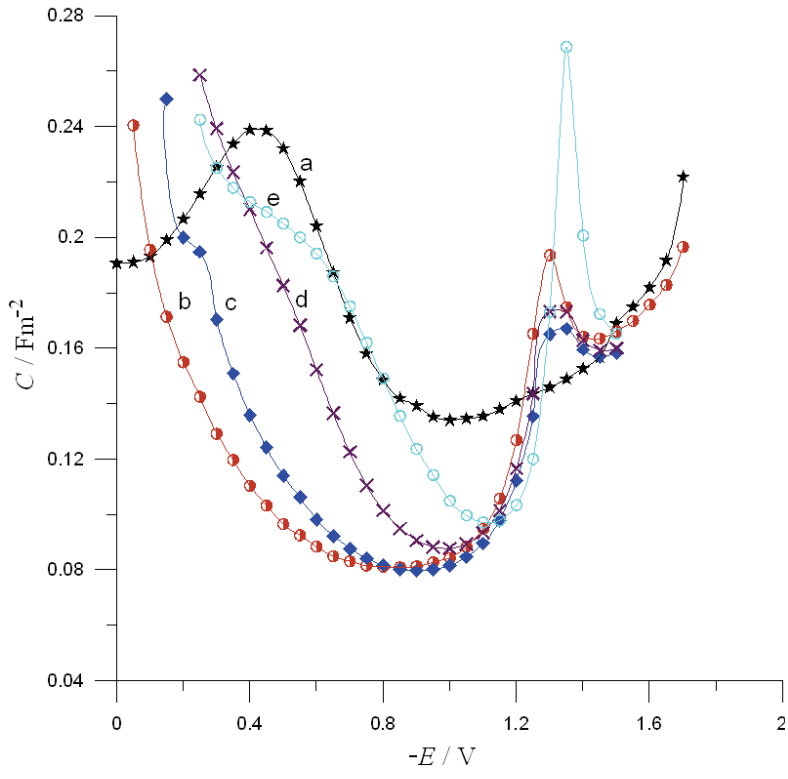

Figure 1. Differential capacity-potential curves extrapolated to zero frequency of: (a) $\mathrm{Hg} / 1 \mathrm{~mol} \mathrm{dm}^{-3} \mathrm{NaClO}_{4}$, (b) $\mathrm{Hg} / 1 \mathrm{~mol}$ $\mathrm{dm}^{-3} \mathrm{NaClO}_{4}+7.5 \times 10^{-4} \mathrm{~mol} \mathrm{dm}^{-3} \mathrm{C}_{11} \mathrm{H}_{26} \mathrm{~N}^{+}$, and $\mathrm{Hg} / 1 \mathrm{~mol}$ $\mathrm{dm}^{-3} \mathrm{NaClO}_{4}+7.5 \times 10^{-4} \mathrm{~mol} \mathrm{dm}^{-3} \mathrm{C}_{11} \mathrm{H}_{26} \mathrm{~N}^{+}+$various TMTU concentrations: (c) 0.0003 , (d) 0.005 , and (e) $0.05 \mathrm{~mol} \mathrm{dm}^{-3}$.

\section{EXPERIMENTAL}

Polarographic and voltammetric curves as well as differential capacity $(C)$ of the double layer, were measured with Autolab (Eco Chemie, The Netherlands). The reproducibility of the average capacity measurements using the ac impedance technique was $\pm 0.5 \%$. The measurements were carried out at several frequencies in the range from $400 \mathrm{~Hz}$ to $2000 \mathrm{~Hz}$, with an amplitude of $5 \mathrm{mV}$. The equilibrium capacities were obtained by extrapolation of the dependence of the measured capacity versus square root of frequency. This procedure as-

Table 1. The values of zero charge potentials, $E_{\mathrm{z}} v s . \mathrm{Ag} / \mathrm{AgCl}$ electrode and surface tension, $\gamma_{\mathrm{z}}$ at $E_{\mathrm{z}}$ for the systems: $1 \mathrm{~mol}$ $\mathrm{dm}^{-3} \mathrm{NaClO}_{4}+7.5 \times 10^{-4} \mathrm{~mol} \mathrm{dm}{ }^{-3} \mathrm{C}_{11} \mathrm{H}_{26} \mathrm{~N}^{+}+\mathrm{TMTU}$

\begin{tabular}{ccc}
\hline $10^{2} c_{\mathrm{TMTU}} / \mathrm{mol} \mathrm{dm}^{-3}$ & $-E_{\mathrm{z}} / \mathrm{V}$ & $\gamma_{\mathrm{z}} / \mathrm{mN} \cdot \mathrm{m}^{-1}$ \\
\hline 0.00 & 0.442 & 411.3 \\
0.03 & 0.418 & 411.3 \\
0.05 & 0.426 & 410.4 \\
0.10 & 0.430 & 402.7 \\
0.30 & 0.468 & 398.3 \\
0.50 & 0.477 & 393.1 \\
1.00 & 0.518 & 388.8 \\
2.00 & 0.569 & 383.6 \\
3.00 & 0.593 & 380.1 \\
4.00 & 0.617 & 379.1 \\
5.00 & 0.634 & 378.4 \\
\hline
\end{tabular}

sumes that the double layer impedance is equivalent to a combination of a capacity-resistance series and that the rate of adsorption is diffusion-controlled. The experiments were performed in a three electrode system with a dropping mercury electrode as a working electrode, $\mathrm{Ag} / \mathrm{AgCl}$ as a reference electrode, and a platinum spiral as a counter - electrode. A controlled growth mercury drop electrode (CGMDE) manufactured by MTM, Poland was used. The potential of zero charge, $E_{z}$, was measured using a streaming electrode. ${ }^{13}$ The interfacial tension $\gamma_{\mathrm{z}}$, at $E_{z}$ was measured by the maximum bubble pressure method according to Schiffrin. ${ }^{14}$ The charge density and surface tension for studied systems: $7.5 \times 10^{-4} \mathrm{~mol} \mathrm{dm}^{-3} \mathrm{C}_{11} \mathrm{H}_{26} \mathrm{NBr}+$ increasing concentration of TMTU from $3 \times 10^{-4}$ to $0.05 \mathrm{~mol} \mathrm{dm}^{-3}$ were obtained by the back integration of differential capacity potential dependences. The maximum concentration of TMTU was limited by its solubility. No corrections to the effects of the medium on the activity of the supporting electrolyte ${ }^{15,16}$ and activity coefficient of the adsorbate ${ }^{17}$ were made. The complex impedance data for $\mathrm{Zn}^{2+}$ ions reduction were collected at 36 frequencies ranging from 100 to $100000 \mathrm{~Hz}$ within the Faradaic potential region with $10 \mathrm{mV}$ intervals. The ohmic resistance of the electrolyte solution was obtained at a potential outside the Faradaic region. Analytical grade $\mathrm{C}_{11} \mathrm{H}_{26} \mathrm{NBr}$, TMTU, and $\mathrm{NaClO}_{4}$ (Fluka) were used without further purification. Water and mercury were double distilled before use. The solutions were deaerated by passing high purity nitrogen over the solutions during the measurements, which were carried out at $298 \pm 0.1 \mathrm{~K}$.

\section{RESULTS AND DISCUSSION}

\section{Experimental Data Analysis}

Figure 1 presents diffential capacity curves obtained experimentally in $1 \mathrm{~mol} \mathrm{dm}^{-3} \mathrm{NaClO}_{4}$, in $1 \mathrm{~mol} \mathrm{dm}^{-3}$ $\mathrm{NaClO}_{4}+7.5 \times 10^{-4}$ mol dm ${ }^{-3} \mathrm{C}_{11} \mathrm{H}_{26} \mathrm{~N}^{+}$, and with the addition of chosen TMTU concentration.

The studied cationic detergent decreased differential capacity in comparison to the one obtained in $1 \mathrm{~mol}$ $\mathrm{dm}^{-3} \mathrm{NaClO}_{4}$. At the potential about $-1.3 \mathrm{~V}$ the desorption peak appeared. The addition of increasing amounts of TMTU caused an increase in differential capacity, but its value was always lower than the one obtained in $1 \mathrm{~mol} \mathrm{dm}^{-3} \mathrm{NaClO}_{4}$. Addition of TMTU don't influence the detergent's desorption peak potential but changed the height of the peak. A similar relations were observed in other systems containing two different organic substances. ${ }^{18,19}$ The change of differential capacity curves indicates that in the presence of $7.5 \times 10^{-4} \mathrm{~mol} \mathrm{dm}^{-3}$ $\mathrm{C}_{11} \mathrm{H}_{26} \mathrm{~N}^{+}$the range of TMTU adsorption potentials doesn't depend on its concentration. Such an effect was not observed in studied systems with TMTU as a com- 
ponent of the mixed adsorption layers so far. As not all of the obtained $C-E$ curves converged at sufficiently negative potentials with the corresponding curve for the base solution, the capacity against potential data were numerically integrated from the point of $E_{\mathrm{z}}$. The integration constants, $E_{\mathrm{z}}$ and $\gamma_{\mathrm{z}}$, are collected in Table 1 . The $E_{\mathrm{z}}$ values shifted towards negative potentials gradually with the increase of TMTU concentration which indicates a TMTU molecule adsorption with its negative pole, that is with the sulfur atom placed on the mercury electrode.

The values of $E_{\mathrm{z}}$ were similar for $c_{\mathrm{TMTU}} \geq 0.01 \mathrm{~mol}$ $\mathrm{dm}^{-3}$ in the detergents absence. ${ }^{10}$ In the cationic detergents presence such $E_{\mathrm{z}}$ values changes are an experimental novelty and point to different adsorptiondesorption equilibria. The $\gamma_{\mathrm{z}}$ values decreased in a comparable way to the changes in the detergents absence. ${ }^{10}$ The data obtained by the integration of differential capacity curves were subsequently used to calculate Parsons' auxiliary function $\xi=\gamma+q E$, where $q$ is the electrode charge and $E$ is the electrode potential. ${ }^{20,21}$ This function was used to calculate the summarized surface excess, $\Gamma$ based on the dependence:

$$
\Gamma=-\frac{1}{R T}\left(\frac{\partial \xi}{\partial \ln c}\right)_{\mathrm{q}}
$$

where $c$ is the bulk concentration of TMTU. The adsorption of $\mathrm{ClO}_{4}^{-}$ions was demonstrated earlier ${ }^{22}$ and the detergents adsorption was obvious. Therefore the adsorption of TMTU in the detergents presence was described using the relative surface excess, $\Gamma^{\prime}$ which, according to Gibbs adsorption isotherm, is given by:

$$
\Gamma^{\prime}=\frac{1}{R T}\left(\frac{\partial \Phi}{\partial \ln c}\right)_{q}
$$

where $\Phi$ is the surface pressure: $\Phi=\Delta \xi=\xi_{0}-\xi\left(\xi_{0}\right.$ is the value of Parsons' auxiliary function for the base electrolyte: $1 \mathrm{~mol} \mathrm{dm}^{-3} \mathrm{NaClO}_{4}+7.5 \times 10^{-4} \mathrm{~mol} \mathrm{dm}^{-3}$ $\mathrm{C}_{11} \mathrm{H}_{26} \mathrm{~N}^{+}$, and $\xi$ is the same function for systems containing TMTU). The obtained $\Gamma$ values were greater for defined TMTU concentration than $\Gamma^{\prime}$ values. This indicates that the adsorption of TMTU molecule pushes out water instead of the detergents molecule from the electrode surface. The $\Gamma^{\prime}$ values obtained in the studied systems are presented in Figure 2.

The values of $\Gamma^{\prime}$ increased with increasing electrode charge more strongly as the TMTU concentration increased in the bulk. The dependencies $\Gamma^{\prime}=\mathrm{f}(q)$ for lower TMTU concentrations were similar both in the detergents presence and absence. This leads us to the conclusion that the cationic detergent did not hinder TMTU adsorption.

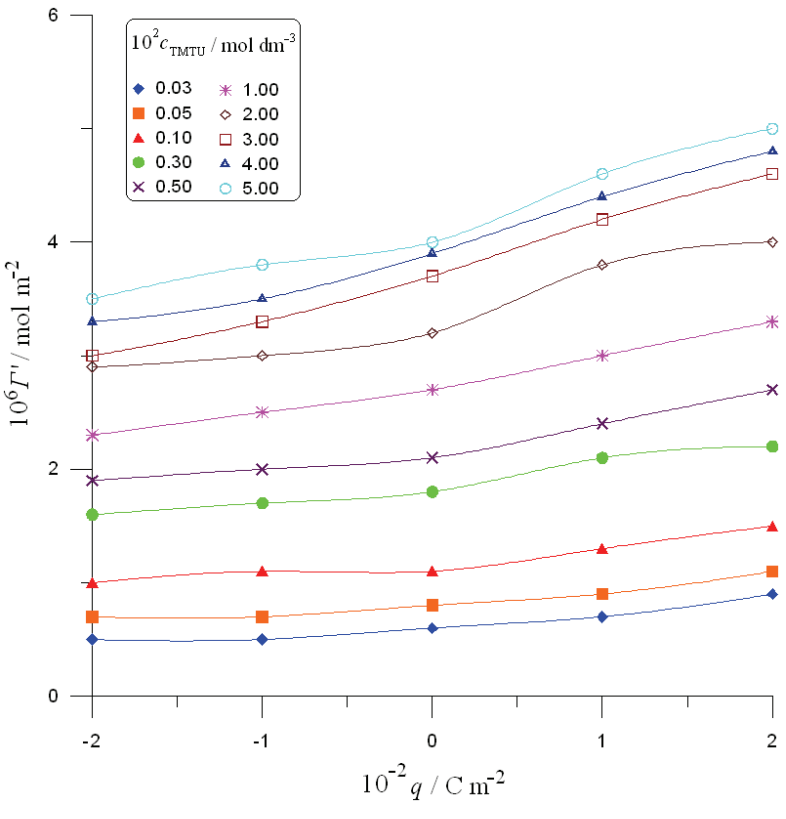

Figure 2. Relative surface excess of TMTU as a function of the electrode charge and TMTU concentration in the bulk.

\section{Adsorption Isotherms}

TMTU adsorption parameters in the presence of the cationic detergent were calculated based on Frumkin and corrected Flory-Huggins ${ }^{23-26}$ isotherms. The Frumkin isotherm constants were determined from the equation:

$$
\beta x=\frac{\Theta}{1-\Theta} \exp (-2 A \Theta)
$$

where $x$ is the molar fraction of TMTU in the solution, $\beta$ is the adsorption coefficient $\left(\beta=\exp \left(-\Delta G^{\mathrm{o}} / R T\right)\right), \Delta G^{\mathrm{o}}$ is the standard Gibbs energy of adsorption, $A$ is the interaction parameter, and $\Theta$ is the coverage $\left(\Theta=\Gamma^{\prime} / \Gamma_{\mathrm{s}}\right)$. The surface excess at saturation $\Gamma_{\mathrm{s}}$ was estimated by extrapolating the $1 / \Gamma^{\prime}$ versus $1 / c_{\mathrm{TMTU}}$ dependence at different electrode charges, to $1 / c_{\mathrm{TMTU}}=0$. The surface occupied by one TMTU molecule $S\left(S \equiv 1 / \Gamma_{\mathrm{s}}\right)$ was $0.137 \mathrm{~nm}^{2}$ and was clearly smaller than in the detergents absence. ${ }^{9}$ Such a small $S$ value could have been the result of TMTU's dipole deformation in the presence of

Table 2. The constants of Frumkin (F) and corrected FloryHuggins isotherm $(\mathrm{H})$ for system: $1 \mathrm{~mol} \mathrm{dm}^{-3} \mathrm{NaClO}_{4}+$ $7.5 \times 10^{-4} \mathrm{~mol} \mathrm{dm}^{-3} \mathrm{C}_{11} \mathrm{H}_{26} \mathrm{~N}^{+}+$TMTU

\begin{tabular}{ccccc}
\hline $10^{2} q / \mathrm{C} \mathrm{m}^{-2}$ & $\Delta G_{F}^{0}$ & $-A_{F}$ & $\Delta G_{H}^{0}$ & $-A_{H}$ \\
\hline+2 & 24.47 & 3.60 & 23.83 & 3.50 \\
+1 & 23.85 & 3.75 & 23.16 & 3.95 \\
0 & 23.46 & 4.35 & 22.81 & 4.40 \\
-1 & 23.28 & 4.65 & 22.64 & 4.85 \\
-2 & 23.23 & 5.30 & 22.59 & 5.18 \\
\hline
\end{tabular}




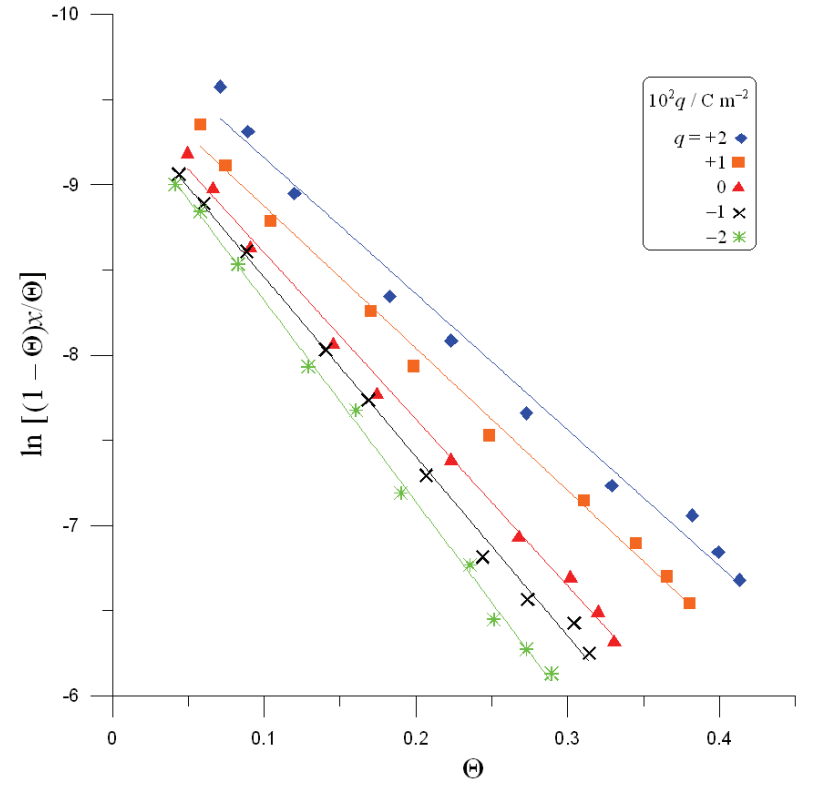

Figure 3. Linear test of the Frumkin isotherm for the system: $1 \mathrm{~mol} \mathrm{dm}^{-3} \mathrm{NaClO}_{4}+7.5 \times 10^{-4} \mathrm{~mol} \mathrm{dm}^{-3} \mathrm{C}_{11} \mathrm{H}_{26} \mathrm{~N}^{+}+\mathrm{TMTU}$

the detergents big molecule. Figure 3 presents the linear test of the Frumkin isotherm for used electrode charges.

The $A$ parameter values were calculated from the line slopes on the linear test of the Frumkin isotherm and the corresponding values of $\Delta G^{\mathrm{o}}$ were determined by the extrapolation of the $\ln [(1-\Theta) x / \Theta] v s$. $\Theta$ curve to the value of $\Theta=0$. The obtained results are presented in Table 2.

The obtained values of free adsorption energy increased in a manner typical for the adsorption i.e. in the

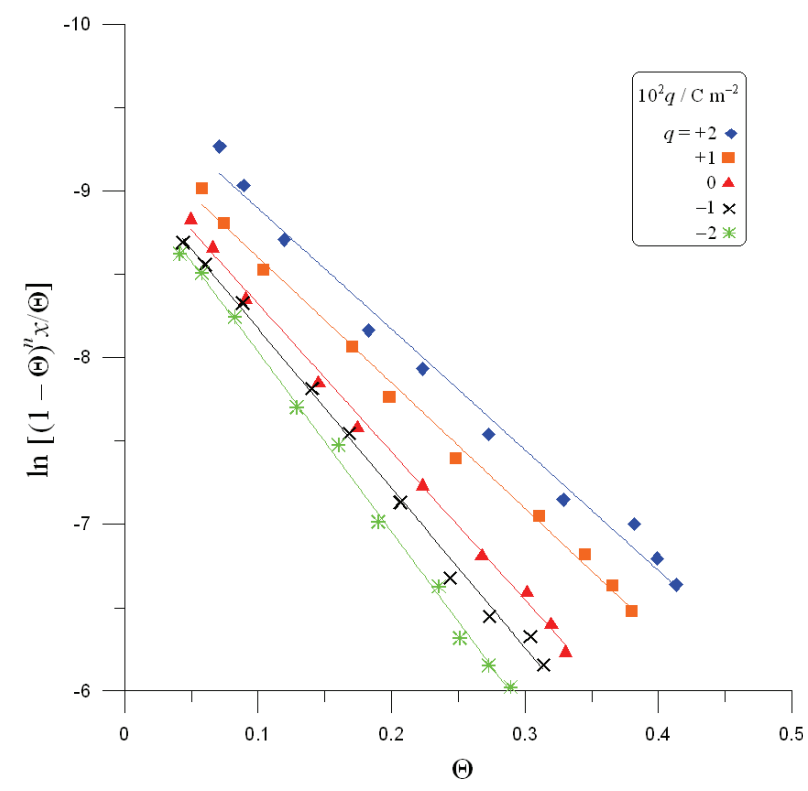

Figure 4. Linear test of the modified Flory-Huggins isotherm for the system: $1 \mathrm{~mol} \mathrm{dm}^{-3} \mathrm{NaClO}_{4}+7.5 \times 10^{-4} \mathrm{~mol} \mathrm{dm}^{-3}$ $\mathrm{C}_{11} \mathrm{H}_{26} \mathrm{~N}^{+}+$TMTU direction of positive charges. The $A$ interaction parameters pointed to repulsive interactions between the adsorbed TMTU molecules decreasing towards the positive electrode charge.

It should be stressed that the obtained $\Delta G^{\mathrm{o}}$ values were clearly smaller than those obtained in the detergents absence. The repulsive interactions between the adsorbed TMTU molecules were considerably stronger than those obtained in detergents absence. The obtained Frumkin isotherm constants pointed to the fact that despite of lower $\Delta G^{\text {o }}$ values and stronger repulsive interactions in the presence of the studied detergent, TMTU's relative surface excess remained unchanged. This could have been the result of weaker hydration of the electrode surface.

TMTU adsorption in the presence of $\mathrm{C}_{11} \mathrm{H}_{26} \mathrm{~N}^{+}$ was further analyzed based on constants obtained from the modified Flory-Huggins isotherm ${ }^{23-26}$ for the longrange particle-particle interaction:

$$
\beta x=\frac{\Theta}{n(1-\Theta)^{n}} \exp (-2 A \Theta)
$$

where $n=1.12$ is the number of water molecules replaced by one TMTU molecule. In the present paper the projected area for water ${ }^{25}$ is $0.123 \mathrm{~nm}^{2}$. As $\mathrm{ClO}_{4}^{-}$ions caused the strongest disruption in water structure, ${ }^{12}$ the surface of one water molecule was used in calculations instead of water clusters.

Figure 4 shows the linear test of the modified Flory-Huggins isotherm for the chosen values of $q$.

The obtained constants of this isotherm are presented in Table 2. The $\Delta G^{\mathrm{o}}$ values were smaller than those obtained from the Frumkin isotherm however the $A$ parameter values were similar. The obtained results from Flory-Huggins isotherm were the result of $n$ value, which was close to one.

\section{The Inner Layer Electrostatic Parameters}

The electrostatic parameters of the inner layer were calculated from the dependence of the potential drop across the inner layer $\Theta^{M-2}$ at constant charge due to the relative surface excess of TMTU (Figure 5). According to Parson's electrostatic model, ${ }^{21}$ the potential $\Theta^{M-2}$ can be described by the following dependence:

$$
\Phi^{M-2}=\frac{4 \pi x_{1}}{\varepsilon_{i}} q+\frac{4 \pi \mu_{\mathrm{TMTU}}}{\varepsilon_{i}} \Gamma^{\prime}
$$

where $\mu_{\mathrm{TMTU}}$ is the dipole moment of an isolated TMTU molecule: $\mu_{\mathrm{TMTU}}=15.7 \times 10^{-30} \mathrm{C} \mathrm{m}^{26}, \varepsilon_{i}$ is the permittivity of the inner layer and $x_{1}$ is the inner layer thickness. The value of $\Theta^{M-2}=E-E_{\mathrm{z}}-\Theta^{2-\mathrm{s}}$, where: $E$ and $E_{\mathrm{z}}$ are 
respectively the measured potential and the potential of the zero charge in the absence of TMTU and $\Theta^{2-s}$ is the potential drop across the diffuse layer, which can be calculated using the Gouy-Chapman theory. The changes in the potential drop across the inner layer presented in Figure 5 are almost linear.

The linear course of the above dependences confirms the congruence of the obtained isotherms with respect to the electrode charge. The results presented in Figure 5 were analyzed in a way similar to that used previously by Jurkiewicz-Herbich ${ }^{28}$ and the values of $\varepsilon_{i}$, integral capacity $-K^{i}$, and $x_{1}$ are presented in Table 3.

The obtained $K^{i}$ value did not depend on the electrode charge just like in the detergents absence ${ }^{10}$ but was considerably lower. Whereas the $\varepsilon_{i}$ values were similar to those obtained in the detergents absence and raised with the increase of electrode charge.

In consequence the inner layer thickness, $x_{1}$ slightly increased with the increasing electrode charge. The large $x_{1}$ value was undoubtedly the result of the cationic detergent molecules length which rose with the increase of electrode charge. This effect was probably the outcome of the repulsive interaction between detergents positive end, and the electrode positively charged surface.

\section{Studies of Adsorption at More Negative Potentials}

The results presented earlier concerning TMTU adsorption in the presence of $\mathrm{C}_{11} \mathrm{H}_{26} \mathrm{~N}^{+}$provided information about the mixed adsorption layers structure and covered these substances potential range of strong adsorption. The studies on kinetics of $\mathrm{Zn}^{2+}$ ion reduction as a piloting ion broaden this range. The necessary values to determine $\mathrm{Zn}^{2+}$ ions reduction in the studied systems changed as follows:

- $\mathrm{Zn}^{2+}$ ions approximate diffusion coefficients $\left(\mathrm{D}_{\mathrm{ox}}\right)$ in the examined solutions were calculated from limiting currents using the Ilkovič equation. The values of $\mathrm{D}_{\mathrm{ox}}$ slightly increased from $6.6 \times 10^{-6} \mathrm{~cm}^{2} \mathrm{~s}^{-1}$ to $6.8 \times 10^{-6} \mathrm{~cm}^{2} \mathrm{~s}^{-1}$. The used organic substances decreased the solutions viscosity. The zinc diffusion coefficient value $\left(D_{\text {red }}\right)$, which was required for further calculations was taken from the literature ${ }^{29}$ as equal to $1.67 \times 10^{-5} \mathrm{~cm}^{2} \mathrm{~s}^{-1}$.

- The difference between potentials of anodic and cathodic peaks on cyclic voltammetric curves, $\Delta E$ changed from $65 \mathrm{mV}$ for $\mathrm{Zn}^{2+}$ in $1 \mathrm{~mol} \mathrm{dm}{ }^{-3} \mathrm{NaClO}_{4}$ to $512 \mathrm{mV}$ for $\mathrm{Zn}^{2+}$ in the presence of $7.5 \times 10^{-4} \mathrm{~mol}$ $\mathrm{dm}^{-3} \mathrm{C}_{11} \mathrm{H}_{26} \mathrm{~N}^{+}$to $38 \mathrm{mV}$ after the addition of $5 \times 10^{-2}$ mol dm ${ }^{-3}$ TMTU. The obtained results allowed a quality based assessment of reduction kinetics of $\mathrm{Zn}^{2+}$ ions in the studied systems: the used concentration of cationic detergent inhibited strongly the electrons transfer however the introduction of higher concentrations of TMTU compensated this inhibition and even accelerated the $\mathrm{Zn}^{2+}$ ions electroreduction process.

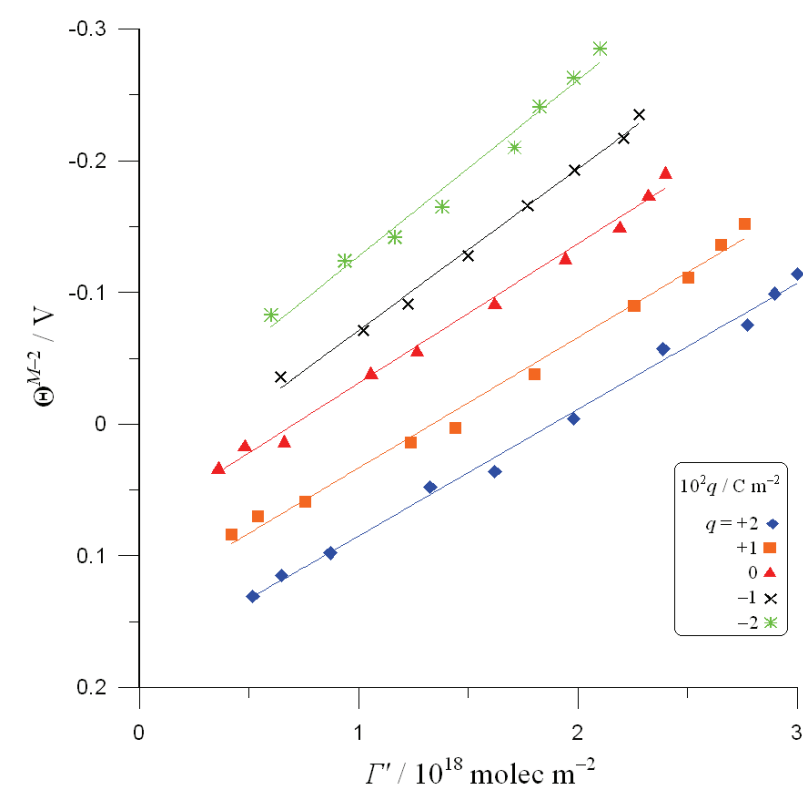

Figure 5. Potential drop across the inner layer $\Theta^{M-2}$ as a function of the surface concentrations of TMTU adsorbed at constant electrode charges for $1 \mathrm{~mol} \mathrm{dm}^{-3} \mathrm{NaClO}_{4}+7.5 \times 10^{-4} \mathrm{~mol}$ $\mathrm{dm}^{-3} \mathrm{C}_{11} \mathrm{H}_{26} \mathrm{~N}^{+}+$TMTU.

- The addition of $7.5 \times 10^{-4} \mathrm{~mol} \mathrm{dm}{ }^{-3} \mathrm{C}_{11} \mathrm{H}_{26} \mathrm{~N}^{+}$to the $\mathrm{Zn}^{2+}$ solution caused the shift of the formal potential, $E_{f}^{0}$, from $-0.960 \mathrm{~V}$ to $-1.01 \mathrm{~V}$ however the addition of increasing amounts of TMTU caused the $E_{f}^{0}$ final shift to $-0.950 \mathrm{~V}$. Figure 6 presents a logarithmic dependence, apparent standard rate constant, $k_{\mathrm{s}}^{\text {app }}$ of $\mathrm{Zn}^{2+}$ ions reduction on TMTU concentration. The determined $k_{\mathrm{s}}^{\text {app }}$ values are a quantitative confirmation of the mentioned above effects concerning $\Delta E$ and $E_{f}^{0}$ value changes. A compensation for the inhibiting and accelerating effect was obtained for the bulk concentrations ratio $c_{\mathrm{TMTU}}: c_{\text {detergent }}=250$. It is worth pointing out that even the smallest TMTU concentration of TMTU clearly decreased the cationic detergents inhibiting activity. Whereas the largest tested TMTU concentration to a much higher degree caused a $\mathrm{Zn}^{2+}$ ions electroreduction acceleration effect in the cationic detergents presence than in its absence.

Table 3. Inner layer properties for the system: $1 \mathrm{~mol}$ $\mathrm{dm}^{-3} \mathrm{NaClO}_{4}+7.5 \times 10^{-4} \mathrm{~mol} \mathrm{dm}{ }^{-3} \mathrm{C}_{11} \mathrm{H}_{26} \mathrm{~N}^{+}+$TMTU, $10^{2} \mathrm{q} /$ $\mathrm{C} \mathrm{m}^{-2}$

\begin{tabular}{|c|c|c|c|c|c|}
\hline \multirow[b]{2}{*}{$q$} & \multirow[b]{2}{*}{$\varepsilon_{i}$} & \multicolumn{2}{|l|}{$\Gamma^{\prime}=0$} & \multicolumn{2}{|l|}{$\Gamma^{\prime}=1$} \\
\hline & & $10^{2} K^{i} / \mathrm{F} \mathrm{m}^{-2}$ & $x_{1} / \mathrm{nm}$ & $10^{2} K^{i} / \mathrm{F} \mathrm{m}^{-2}$ & $x_{1} / \mathrm{nm}$ \\
\hline-2 & 14.17 & 8.33 & 1.50 & 9.09 & 1.38 \\
\hline-1 & 14.17 & 8.33 & 1.50 & 9.09 & 1.38 \\
\hline 0 & 16.55 & 8.33 & 1.76 & 9.09 & 1.61 \\
\hline 1 & 17.71 & 8.33 & 1.88 & 9.09 & 1.72 \\
\hline 2 & 18.64 & 8.33 & 1.98 & 9.09 & 1.81 \\
\hline
\end{tabular}




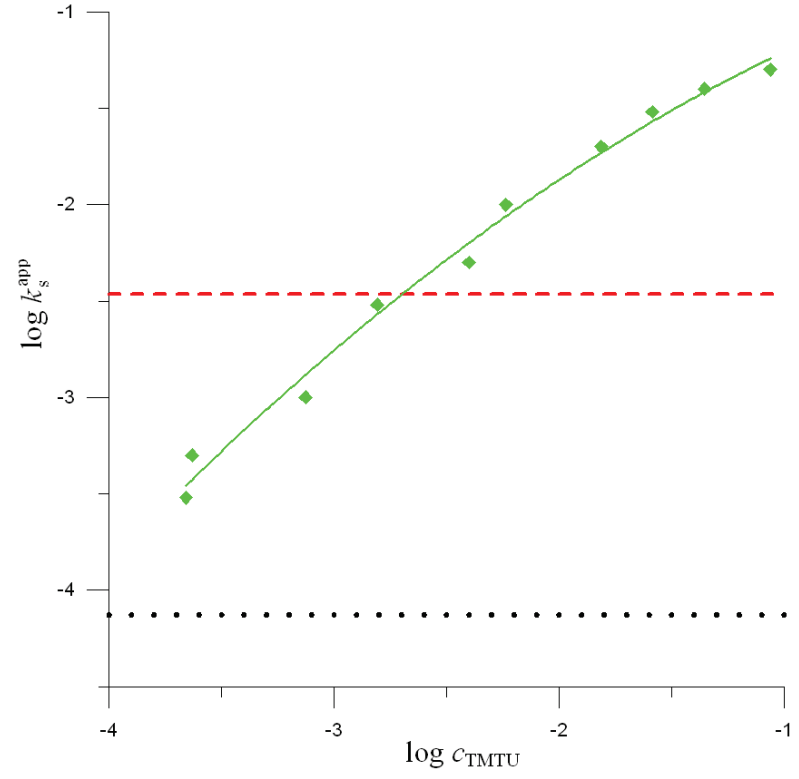

Figure 6. Plots of $\log \sqrt{k_{\mathrm{s}}^{\text {app }}}$ for the $5 \times 10^{-3} \mathrm{~mol} \mathrm{dm}^{-3} \mathrm{Zn}^{2+}$ in $1 \mathrm{~mol} \mathrm{dm}^{-3} \mathrm{NaClO}_{4}$ (the dashed line), $1 \mathrm{~mol} \mathrm{dm}^{-3} \mathrm{NaClO}_{4}+$ $5 \times 10^{-3} \mathrm{~mol} \mathrm{dm}^{-3} \mathrm{Zn}^{2+}+7.5 \times 10^{-4} \mathrm{~mol} \mathrm{dm}{ }^{-3} \mathrm{C}_{11} \mathrm{H}_{26} \mathrm{~N}^{+}$(the dotted line) and with the addition of various TMTU concentrations (the continous line).

- The kinetic measurements confirmed the mixed adsorption layers presence on the mercury electrode surface even in the potential range of $-1.0 \mathrm{~V}$ in which it was impossible to calculate adsorption parameters by means of the thermodynamic method.

\section{CONCLUSIONS}

Based on the TMTU adsorption measurements in the cationic detergents presence and $\mathrm{Zn}^{2+}$ reduction kinetics in the studied systems, the following statements referring to the mixed adsorption layer on the mercury electrode can be made:

1. By comparing the summarized surface excess, $\Gamma$, and the relative surface excess, $\Gamma^{\prime}$, it followed that the adsorbing itself TMTU molecule pushed out the water molecule instead of the detergents molecule from the electrode surface.

2. The presence of $7.5 \times 10^{-4} \mathrm{~mol} \mathrm{dm}{ }^{-3} \mathrm{C}_{11} \mathrm{H}_{26} \mathrm{~N}^{+}$at the electrode surface to a small degree influenced the surface TMTU concentration.

3. The small surface occupied by one TMTU molecule in the cationic detergents presence might have been a sign of a strong deformation of that molecule.

4. The constants of the Frumkin and corrected FloryHuggins isotherm point to a decreased TMTU adsorption energy in the cationic detergents presence and stronger repulsive interaction.

5. The linear changes of $\Theta^{M-2} v s . \Gamma_{\text {тмтU }}^{\prime}$ confirmed the congruence of the obtained isotherms with respect to the electrode charge

6. The permittivity, $\varepsilon_{i}$ of the inner layer was similar to the one obtained in the detergents absence.

7. Bigger accelerating effect on $\mathrm{Zn}^{2+}$ ion electroreduction caused by TMTU in the presence of $7.5 \times 10^{-4}$ mol dm${ }^{-3} \mathrm{C}_{11} \mathrm{H}_{26} \mathrm{~N}^{+}$than just in $1 \mathrm{~mol} \mathrm{dm}{ }^{-3} \mathrm{NaClO}_{4}$ was a confirmation of earlier observations ${ }^{30,31}$ and might have been the result of a weaker electrode surface hydration during adsorption of the used organic substances.

\section{REFERENCES}

1. L. H. Dubois and R.G. Nuzzo, Annu. Rev. Phys. Chem. 43 (1992) $437-463$.

2. A. Ulman, Chem. Rev. 96 (1996) 1533-1554.

3. C. D. Bain and G. M. Whitesides, J. Am. Chem. Soc. 110 (1988) 6560-6561.

4. L. Bertilsson and B. Liedberg, Langmuir 9 (1993) 141-149.

5. J. P. Folkers, P. E. Leibnis, G. M. Whitesides, and J. Deutch, J. Phys. Chem. 98 (1994) 563-571.

6. L. M. Doubova, A. De Batisti, S. Daolio, and S. Trasatti, J. Electroanal. Chem. 500 (2001) 134-146.

7. A. Łukomska and J. Sobkowski, Polish J. Chem. 78 (2004) 1135-1147.

8. R. Słojkowska, B. Pałys, and M. Jurkiewicz-Herbich, Electrochim. Acta 49 (2004) 4109-4118.

9. O. Ikeda, H. Jimbo, and H. Tamura, J. Electroanal. Chem. 137 (1982)127-141.

10. D. Gugała, Z. Fekner, D. Sieńko, J. Nieszporek, and J. Saba, Electrochim. Acta 49 (2001) 2227-2236.

11. D. Sieńko, D. Gugała-Fekner, J. Nieszporek, Z. Fekner, and J. Saba, Collect. Czech. Chem. Commun. 74 (2009) 1309-1321.

12. J. Koryta, J. Dvorak, and V. Bohackova, Elektrochemia, PWN, Warszawa, 1980, p. 30.

13. D. C. Grahame, R. P. Larsen, and M. A, Poth, J. Am. Chem. Soc. 71 (1949) 2978-2983.

14. D. J. Shiffrin, J. Electroanal. Chem. 23 (1952) 168-171.

15. A. De Batisti and S. Trasatti, J. Electranal. Chem. 54 (1974) 1-17.

16. D. M. Mohilner and H. Nakadomari, J. Phys. Chem. 77 (1973) 1594-1595.

17. D. M. Mohilner, L. W. Browman, S. J. Freeland, and H. J. Nakadomari, J. Electrochem. Soc. 120 (1973) 1658-1662.

18. K. Eda and K. Takahashi, J. Chem. Soc. Japan 85 (1964) 828- 832.

19. S. L. Gupta and S. K. Sharma, Electrochim. Acta 10 (1965) 151-158.

20. R. Parsons, Trans. Faraday Soc. 51 (1955) 1518-1529.

21. R. Parsons, Proc. Roy. Soc. A 261 (1961) 79-90.

22. W. R. Fawcett, R. C. Rocha-Filho, and L. M. Doubova, J. Chem. Soc. Faraday Trans. 87 (1991) 2967-2970.

23. P. J. Flory, J. Chem. Phys. 10 (1942) 51-61.

24. R. Parsons, J. Electroanal. Chem. 8 (1964) 93-98.

25. J. Lawrence and R. Parsons, J. Phys. Chem. 73 (1969) 3577-3581.

26. S. Trasatti, J. Electroanal. Chem. 28 (1970) 257-277.

27. A. Lüttringhaus and J. Grohmann, Z. Naturforsch. 10B (1955) 365-367.

28. M. Jurkiewicz-Herbich and J. Jastrzębska, Pol. J. Chem. 58 (1984) 1125-1137.

29. N. S. Furman and W. Ch. Cooper, J. Am. Chem. Soc. 72 (1950) 5667-5676.

30. J. Saba, Electrochim. Acta 39 (1994) 711-717.

31. J. Saba, Electrochim. Acta 41 (1996) 297-306. 